\title{
1. Origins of Small Proton Chemical Shift Differences in 2 Monodeuterated Methyl Groups
}

\author{
${ }_{3}$ O. Maduka Ogba, ${ }^{\dagger}$ Stuart J. Elliott, ${ }^{\ddagger}$ David A. Kolin, ${ }^{\dagger}$ Lynda J. Brown, ${ }^{\ddagger}$ Sebastian Cevallos, ${ }^{\dagger}$ \\ ${ }_{4}$ Stuart Sawyer, ${ }^{+}$Malcolm H. Levitt, ${ }^{\ddagger 0}$ and Daniel J. O’Leary*, ${ }^{\dagger}$ \\ $5{ }^{\dagger}$ Department of Chemistry, Pomona College, 645 North College Avenue, Claremont, California 91711, United States \\ $6{ }^{\ddagger}$ School of Chemistry, University of Southampton, Southampton SO17 1BJ, United Kingdom
}

\section{S Supporting Information}

8 ABSTRACT: We have recently shown that the small proton chemical shift difference 9 in 2-methyl-1-(methyl- $d$ )piperidine supports a long-lived nuclear spin state. To identify 10 additional candidate molecules with $\mathrm{CH}_{2} \mathrm{D}$ groups exhibiting accessible long-lived 11 states, and to investigate the factors governing the magnitude of the shift differences, we 12 report a computational and experimental investigation of methyl rotational dynamics 13 and proton chemical shifts in a variety of 2-substituted 1-(methyl- $d$ )piperidines. The 14 polarity and size of the 2-substituent affect the 1,2-stereoisomeric relationship and consequently the strength of the rotational asymmetry within the $\mathrm{CH}_{2} \mathrm{D}$ group. Nonpolar and large 2-substituents prefer the equatorial position, and relatively large shift differences (i.e., > $13 \mathrm{ppb}$ ) are observed. Polar and small substituents, however, increasingly prefer the axial position, and medium to small shift differences (i.e., 0 to $9 \mathrm{ppb}$ ) are observed. In addition, diastereotopic $\mathrm{CH}_{2} \mathrm{D}$ proton chemical shift difference for tricarbonyl(1-chloro-2-deuteriomethylbenzene) chromium(0) was computed, showing that reasonable predictions of these small shift differences can be extended to more complex, organometallic species.

\section{INTRODUCTION}

22 The discovery of long-lived nuclear spin states (LLS $)^{1-3}$ in a 23 variety of molecular systems has attracted significant interest. 24 LLS lifetimes often surpass the characteristic relaxation time of 25 ordinary magnetization $\left(T_{1}\right)$ by an order of magnitude. ${ }^{2}$ LLS 26 are particularly promising in combination with the large 27 sensitivity improvements afforded by NMR hyperpolarizatio$28 \mathrm{n}^{3,4 a}$ Applications benefiting from substantial NMR signal 29 enhancements include: imaging and monitoring of cancer in 30 human patients, ${ }^{4 a}$ targeting molecules relevant to neuro31 science, ${ }^{4 \mathrm{~b}}$ protein unfolding mechanisms, ${ }^{4 \mathrm{c}}$ and measuring 32 slow diffusion coefficients of large biomolecules. ${ }^{4 \mathrm{~d}}$

33 The generation of long-lived states typically requires 34 combining radiofrequency pulse sequences with chemically 35 inequivalent and scalar coupled nuclei. The extension of these 36 techniques to methyl groups requires $\mathrm{CH}_{2} \mathrm{D}$ groups consisting 37 of diastereotopic protons with different chemical shifts. For 38 technical reasons that relate to LLS pulse sequences, ${ }^{2 \mathrm{~d}, \mathrm{f}}$ very 39 small chemical shift differences $(<20 \mathrm{ppb})$ were viewed as 40 particularly ideal. We have recently shown that a LLS is 41 supported in the monodeuterated methyl groups of two 42 molecules: 2-methyl-1-(methyl- $d$ ) piperidine ${ }^{5}$ and tricarbonyl43 (1-chloro-deuteriomethylbenzene) chromium $(0){ }^{6}$ Both LLS 44 were accessed via small proton chemical shift differences (ca. 4513 and $8 \mathrm{ppb}$, respectively) between the diastereotopic protons 46 of their corresponding $\mathrm{CH}_{2} \mathrm{D}$ groups (Figure 1).

47 To the best of our knowledge, there are only three reported 48 cases shown to induce chemical shifts between diastereotopic 49 protons of the $\mathrm{CH}_{2} \mathrm{D}$ group, ${ }^{7-10}$ and little is known about the 50 factors governing the magnitude of these shift differences. In
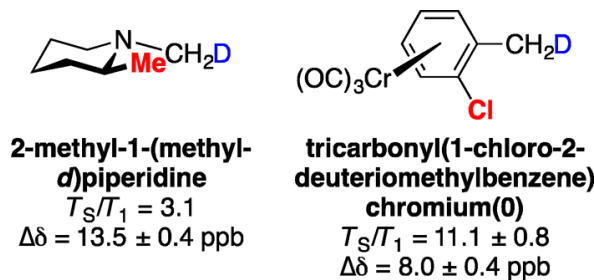

Figure 1. Ratios of $T_{\mathrm{S}}$, the singlet order relaxation time constant, and $T_{1}$, the longitudinal relaxation time constant, and the small chemical shift differences $(\Delta \delta)$ for the diastereotopic $\mathrm{CH}_{2} \mathrm{D}$ protons of 2methyl-1-(methyl- $d$ )piperidine and tricarbonyl(1-chloro-2deuteriomethylbenzene) chromium $(0)$.,6 $^{5,6}$

the case of 2-methyl-1-(methyl- $d$ ) piperidine, previous measure- 51 ments and predictions by Anet and Kopelevich, ${ }^{7}$ and 52 computations by us, ${ }^{8,9}$ have shown that due to hyper- 53 conjugation effects between the lone pair of the piperidine 54 nitrogen and an anti-methyl C-H(D) bond, and the local chiral 55 environment around the $\mathrm{CH}_{2} \mathrm{D}$ group, an asymmetric 56 population distribution of the three $\mathrm{CH}_{2} \mathrm{D}$ rotamers is achieved. 57 This results in a small secondary equilibrium isotope effect and 58 corresponds to a shift difference between the $\mathrm{CH}_{2} \mathrm{D}$ protons, 59 observed using ${ }^{1} \mathrm{H}$ NMR spectroscopy.

Encouraged by these results, we set out to explore a variety of 61 2-substituted 1-(methyl-d)piperidines (Figure 2). Our goal was $62 \mathrm{f} 2$ to understand how the steric and electronic nature of the 2- 63

Received: June 1, 2017

Published: July 26, 2017 


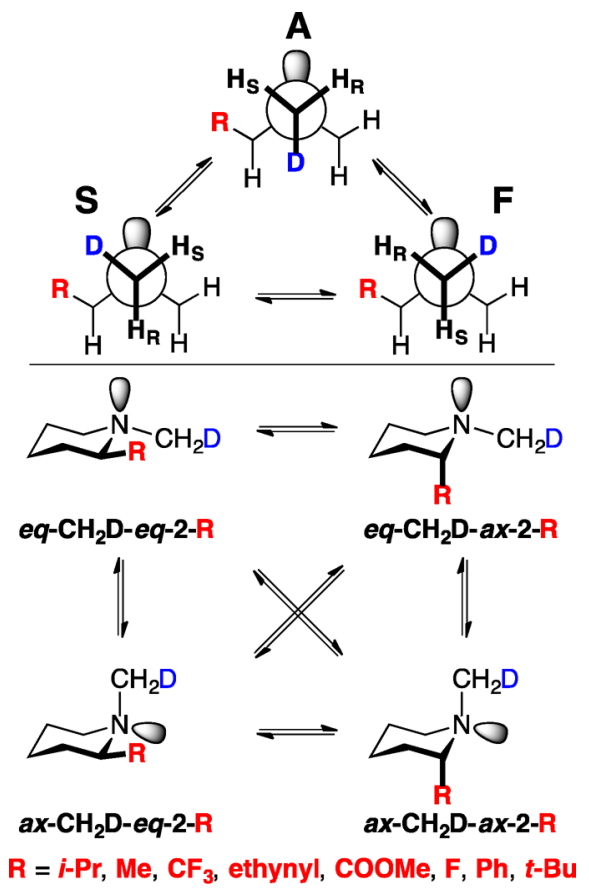

Figure 2. Three $\mathrm{CH}_{2} \mathrm{D}$ rotamers, labeled as deuterium positioned anti to $\mathrm{N}$ lone-pair (A), in steric proximity to $\mathrm{R}$ group (S), and relatively free from steric hindrance of $\mathrm{R}$ group (F) (top). The four stereoisomers of each substituted piperidine (middle). The eight 2substituted 1-(methyl- $d$ )piperidines computed in this study (bottom). substituent perturbs the EIE and proton shift differences in this 64 family of compounds. Through joint computational and 65 experimental efforts, we discovered that, in general, the 66 magnitude of chemical shift difference between $\mathrm{CH}_{2} \mathrm{D}$ protons 67 is affected by the preferred stereoisomeric relationship between 68 the $\mathrm{CH}_{2} \mathrm{D}$ group and the 2-substituent on the piperidine ring. 69 Nonpolar and large 2-substituents prefer the equatorial 70 position, and relatively large shift differences (i.e., > $13 \mathrm{ppb}$ ) 71 are observed. Polar and small substituents, however, increas- 72 ingly prefer the axial position, and medium to small shift 73 differences (i.e., 0 to $9 \mathrm{ppb}$ ) are observed.

We computed the weighted average of shift differences for all 75 populated states in each piperidine species to accurately predict 76 proton chemical shift differences of the kind described above. ${ }^{11} 77$ To accomplish this, a gas-phase conformational search was 78 performed using the Merck Molecular Force Field (MMFFs) ${ }^{12} 79$ as implemented in Schrödinger MacroModel suite. ${ }^{13}$ Quantum 80 mechanical computations in Gaussian $09^{14}$ to obtain refined 81 structures and energies for each conformer were performed at 82 the $\omega \mathrm{B} 97 \mathrm{X}^{15} / \mathrm{cc}-\mathrm{pVTZ}^{16}$ level of theory, including the 83 polarizable continuum model $(\mathrm{PCM})^{17}$ for dichloromethane. 84 All stationary points were verified as minima by a vibrational 85 frequency analysis. For each optimized structure, the 86 thermochemistry of the $\mathrm{CH}_{2} \mathrm{D}$ rotamers were obtained at the 87 same level of theory. NMR isotropic shielding constants, and 88 thus chemical shifts, for each structure were computed at the 89 $\mathrm{HF}^{18} / 6-311+\mathrm{G}(2 \mathrm{~d}, \mathrm{p})^{19,20}$ level of theory including PCM for 90 dichloromethane. $^{21}$ The averaged chemical shift differences 91 were computed as the weighted sum of the chemical shift 92

Table 1. Mole Fractions $(\chi)$ of $\mathrm{CH}_{2} \mathrm{D}$ Rotamers Across Stereoisomers, and Corresponding Computational (comp) and Experimental (exp) Chemical Shift Differences $(\Delta \delta)$ between Prochiral $\mathrm{CH}_{2} \mathrm{D}$ Protons (i.e., $\mathrm{H}_{\mathrm{R}}$ and $\mathrm{H}_{S}$, See Figure 2 ) in Eight 2-Substituted 1-(Methyl-d)piperidine Compounds ${ }^{a}$

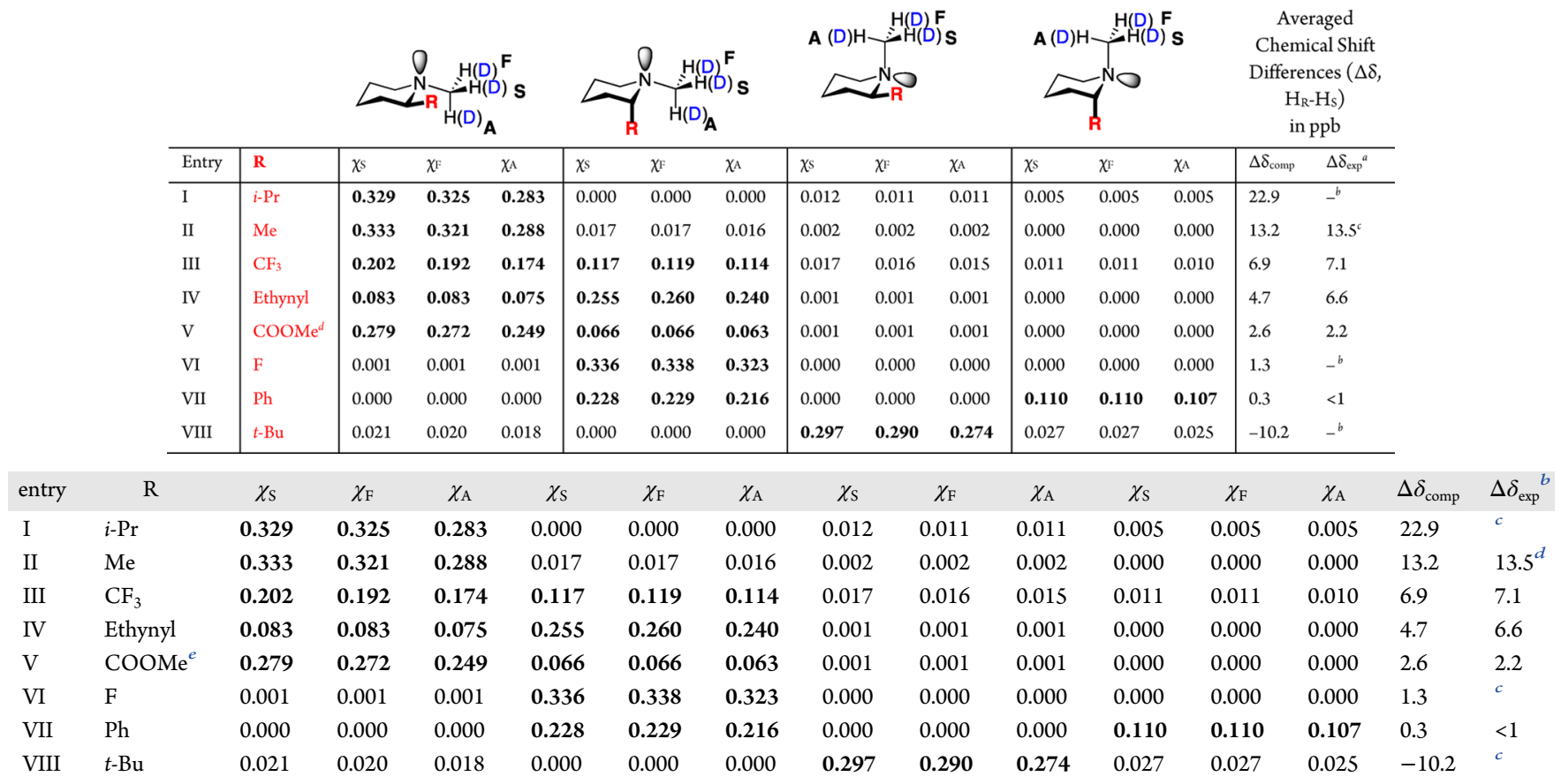

${ }^{a}$ Significant fractional populations of stereosiomers $\left(\chi_{\mathrm{S}+\mathrm{F}+\mathrm{A}}>0.1\right)$ reported in bold. ${ }^{24} .{ }^{b}$ All experimental ${ }^{1} \mathrm{H}$ spectra can be found in the Supporting Information. Experimentally determined chemical shifts reported to $\pm 0.4 \mathrm{ppb}$ precision. ${ }^{c}$ Not prepared. ${ }^{d} \Delta \delta_{\text {exp }}$ for 2 -ethyl-1-(methyl- $d$ )piperidine was also experimentally determined to be $13.7 \pm 0.4 \mathrm{ppb}$. ${ }^{e}$ Multiple conformers were computed for each stereoisomer. Reported mole fractions are from the sum of all computed conformers. $\Delta \delta_{\text {exp }}$ for ethyl 1-(methyl- $d$ )piperidine-2-carboxylate was determined. Methyl derivative was computed to reduce conformational complexity. 
93 difference for each rotamer in each conformer and stereo94 isomer. $^{22,23}$

\section{RESULTS AND DISCUSSION}

96 We studied eight 2-substituted 1-(methyl- $d$ )piperidines. For 97 each piperidine, four possible stereoisomers (denoted as eq$98 \mathrm{CH}_{2} \mathrm{D}$-eq-2-R, eq- $\mathrm{CH}_{2} \mathrm{D}-a x-2-\mathrm{R}, a x-\mathrm{CH}_{2} \mathrm{D}-\mathrm{eq}-2-\mathrm{R}$, and $a x$ $\left.99 \mathrm{CH}_{2} \mathrm{D}-\boldsymbol{a x}-\mathbf{2}-\mathrm{R}\right)$ were computed, and mole fractions for the 100 three corresponding rotamers, S, F, and A were derived (Figure $1012)$. A summary of our results is reported in Table 1.

102 For 2-isopropyl-1-(methyl- $d$ )piperidine and 2-methyl-1103 (methyl- $d$ ) piperidine, 0.94 of the fractional population of states 104 exists as eq- $\mathbf{C H}_{\mathbf{2}} \mathbf{D}$-eq-2-R, consistent with previous reports 105 (Table 1, entries I, II). ${ }^{9}$ In this stereoisomer, a rotameric 106 preference for the deuteron in position $S$ is observed. The 107 origin of this isotope effect is primarily due to an $\mathrm{n} \rightarrow \sigma^{*}$ 108 hyperconjugation interaction between the nitrogen lone-pair 109 and an anti $\mathrm{C}-\mathrm{H}(\mathrm{D}) \sigma$ bond in the $\mathrm{CH}_{2} \mathrm{D}$ group. ${ }^{7,25}$ This 110 stereoelectronic effect serves to weaken the anti $\mathrm{C}-\mathrm{H}(\mathrm{D})$ bond 111 relative to the gauche positions. Evidence of this weakening is 112 observed in the computed stretching frequencies. For example, 113 in 2-isopropyl-1-(methyl- $d$ )piperidine (Table 1, entry I), the 114 computed anti $\mathrm{C}-\mathrm{H}$ stretching frequency $\left(2957 \mathrm{~cm}^{-1}\right)$ is 115 significantly lower than those associated with the gauche 116 positions $\left(3165 \mathrm{~cm}^{-1}\right.$, asymmetrical stretch; $3112 \mathrm{~cm}^{-1}$, 117 symmetrical stretch). To maximize zero-point vibrational 118 stabilization in the molecule, deuterium partitions into the 119 gauche $\mathrm{C}-\mathrm{H}(\mathrm{D})$ bonds (i.e., position $\mathrm{S}$ or $\mathrm{F}$ ). A smaller steric 120 isotope effect, originating from interactions between the 2121 substituent and vicinal $\mathrm{C}-\mathrm{H}(\mathrm{D})$, results in further sequestering 122 of deuterium into position $\mathrm{S}$. Predicted $\Delta \delta$ values of 22.9 and $12313.2 \mathrm{ppb}$ are computed for 2-isopropyl and 2-methyl 124 substituted piperidines, respectively, consistent with experi125 ments $\left(\Delta \delta_{\exp _{23}}=13.5 \pm 0.4 \mathrm{ppb}\right.$ for 2-methyl-1-(methyl$126 d$ )piperidine). ${ }^{23}$

127 For 2-trifluoro-1-(methyl- $d$ ) piperidine, the dominant frac128 tional population of 0.57 exists as $e q-\mathbf{C H}_{2} \mathbf{D}$-eq-2- $\mathrm{R}$. However, a 129 smaller but significant fractional population of 0.35 exists as eq$130 \mathbf{C H}_{2} \mathbf{D}$-ax-2-R (Table 1, entry III). We attribute this 131 distribution to a competing stabilizing hyperconjugation 132 between the $N$ lone pair and the anti $\mathrm{C}-\mathrm{C} \sigma^{*}$ orbital at the 133 2-position (i.e., the anomeric effect, ${ }^{26}$ see Figure 5). We observe 134 a weakened rotameric asymmetry, caused by a diminished lone 135 pair- $\mathrm{CH}_{2} \mathrm{D}$ interaction, and a smaller proton chemical shift 136 difference in these species. $\Delta \delta_{\text {comp }}$ of 6.9 is computed for 2137 trifluoro-1-(methyl- $d$ )piperidine, consistent with experiments $138\left(\Delta \delta_{\text {exp }}=7.1 \pm 0.4 \mathrm{ppb}\right)$.

139 For 2-ethynyl-1-(methyl- $d$ )piperidine, 2-fluoro-1-(methyl- $d$ )140 piperidine and 2-phenyl-1-(methyl- $d$ )piperidine, we observe a 141 switch in stereoisomeric preference as the dominant fractional 142 population exists as eq- $\mathbf{C H}_{2} \mathbf{D}-\boldsymbol{a x}-\mathbf{2}-\mathbf{R}(0.76,>0.99$, and 0.67 , 143 respectively, see Table 1 , entries IV, VI, and VII). Relatively 144 small $\Delta \delta_{\text {comp }}$ values of $4.7,1.3$, and $0.3 \mathrm{ppb}$ are computed for 2145 ethynyl, 2-fluoro, and 2-phenyl substituted piperidines. The $146 \Delta \delta_{\text {exp }}$ for 2-phenyl-1-(methyl- $d$ )piperidine was not experimen147 tally observed, suggesting that the magnitude is $<1 \mathrm{ppb}$.

148 The dominant fractional population of stereoisomers in 149 methyl 1-(methyl-d)piperidine-2-carboxylate exists as eq$150 \mathbf{C H}_{2} \mathbf{D}$-eq-2-R (Table 1, entry V) as seen in the 2-isopropyl, 151 2-methyl, and 2-trifluoromethyl substituted derivatives (Table 152 1, entries I, II, and III). However, the magnitude of computed 153 and experimentally observed $\Delta \delta$ for methyl 1-(methyl$154 d)$ piperidine-2-carboxylate is relatively small $\left(\Delta \delta_{\text {comp. }}=2.6\right.$ ppb, $\left.\Delta \delta_{\text {exp. }}=2.2 \pm 0.4 \mathrm{ppb}\right)$. Measurement of such small 155 chemical shift differences necessitated a least-squares fitting 156 procedure in which the low-intensity outer lines of the $A B \quad 157$ quartet are fit using $\Delta \delta$ and ${ }^{2} J$ as adjustable parameters. (Figure $158 \mathrm{f} 3$ $3) .{ }^{27}$ The origin of this deviation can be seen by comparing the $159 \mathrm{f} 3$

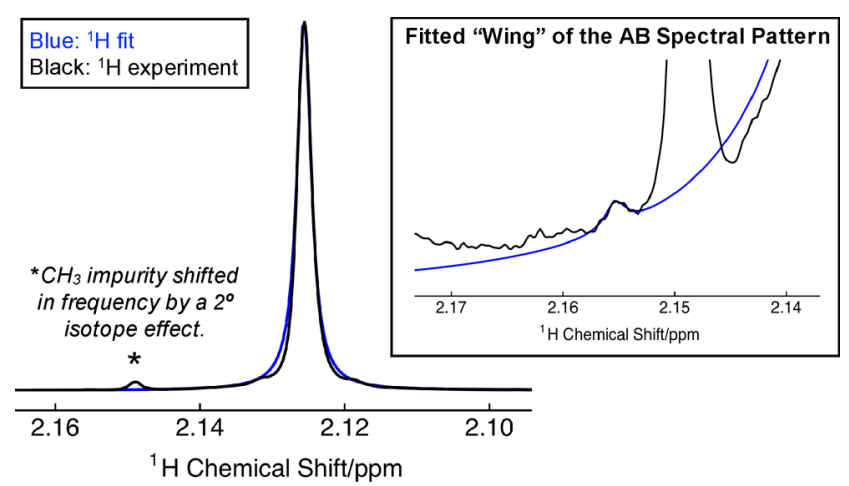

Figure 3. Small chemical shift difference for ethyl 1-(methyld)piperidine-2-carboxylate is estimated via a least-squares fitting of the experimental spectrum using $\Delta \delta(2.2 \pm 0.6 \mathrm{ppb})$ and ${ }^{2} J(11.7 \mathrm{~Hz})$ as adjustable parameters. ${ }^{27}$

difference in shielding constants between a proton at the $S$ and 160 $\mathrm{F}$ rotameric positions (i.e., $\delta_{\mathrm{S}}-\delta_{\mathrm{F}}$ ) of the dominant stereo- 161 isomer in the four species (Figure 4). The relatively small $162 \mathrm{f} 4$
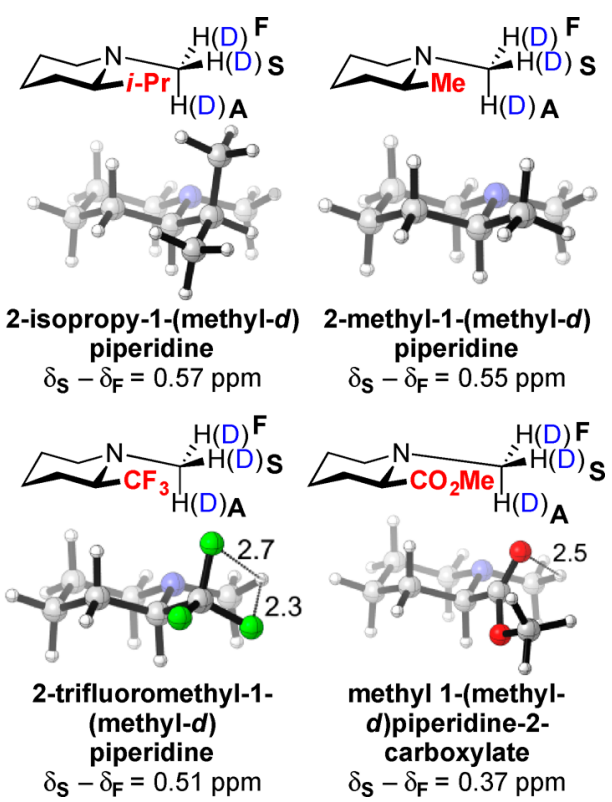

Figure 4. Difference in shielding constants at the $\mathrm{S}$ and $\mathrm{F}$ positions in the dominant stereoisomer of four 2-substituted 1-(methyl- $d$ )piperidine. Optimized structures are illustrated using CYLview, ${ }^{28}$ with distances reported in Ångströms. ${ }^{24}$

$\delta_{\mathrm{S}}-\delta_{\mathrm{F}}$ value for methyl 1-(methyl- $d$ )piperidine-2-carboxylate 163 may be ascribed to a $\mathrm{CH}$... O interaction ${ }^{29}$ between the ester 164 carboxyl oxygen and an $\mathrm{N}$-methyl $\mathrm{H}$ (or D), which contributes 165 to deshielding effects at the $S$ position, thereby, reducing the 166 overall difference in magnetic environment between the $H_{R}$ and 167 $\mathrm{H}_{\mathrm{S}}$ protons. $^{30}$

168

In the case of 2-tert-butyl-1-(methyl- $d$ )piperidine, the 169 dominant fractional population of 0.86 exists as $\boldsymbol{a x}-\mathbf{C H}_{2} \mathbf{D}$-eq- 170 2-R (Table 1, entry VIII). This stereoisomeric preference can 171 
172 be readily explained by the difference in A-values of methyl and 173 tert-butyl ring substituents. ${ }^{31}$ Furthermore, eq- $\mathbf{C H}_{2} \mathbf{D}$-eq-2-R is 174 disfavored over the most stable stereoisomer by $2.4 \mathrm{kcal} / \mathrm{mol}$ 175 due to a more severe $t$ - $\mathrm{Bu} / \mathrm{Me}$ gauche interaction. Interestingly, 176 in the preferred stereoisomer, we still observe a rotameric 177 preference for deuterium in the $\mathrm{S}$ position over the $\mathrm{F}$ (or A) 178 position, suggesting that the $t$-Bu is bulky enough to affect the 179 isotopically perturbed system as seen in previous cases above. A $180 \Delta \delta$ of $-10.2 \mathrm{ppb}$ is predicted through computations. The 181 negative $\Delta \delta$ stems from the computed proton chemical shifts at 182 the $\mathrm{CH}_{2} \mathrm{D}$ rotameric positions $(\mathrm{S}, \mathrm{F}$, and $\mathrm{A})$ in $\boldsymbol{a x}-\mathrm{CH}_{2} \mathrm{D}$-eq-2$183 \mathbf{R}$ with respect to those in eq- $\mathbf{C H}_{2} \mathbf{D}$-eq-2-R. In 2-tert-butyl-1184 (methyl- $d$ ) piperidine, where $\boldsymbol{a x}$ - $\mathbf{C H}_{2} \mathbf{D}$-eq-2-R is dominant, $\mathrm{S}=$ $1852.29, \mathrm{~F}=1.81$, and $\mathrm{A}=2.41 \mathrm{ppm}$, while in eq- $\mathbf{C H}_{2} \mathbf{D}-\mathbf{e q}-\mathbf{2}-\mathrm{R}, \mathrm{S}$ $186=2.73, \mathrm{~F}=1.93$, and $\mathrm{A}=1.75 \mathrm{ppm}^{23}$ The shielding of $\mathrm{A}$ with 187 respect to $S$ and $F$ in the former is switched in the latter, 188 resulting in a switch in sign of $\Delta \delta$.

189 Considering the results above, we build on the model 190 previously established for evaluating and predicting equilibrium 191 isotope effects and diastereotopic chemical shift differences in 192 2-substituted 1-(methyl- $d$ )piperidines. Specifically, we add that 193 the stereoisomeric relationship between the $\mathrm{CH}_{2} \mathrm{D}$ group and 194 2-substituents is crucial. Nonpolar and large alkyl substituents 195 at the 2-position tend to favor the equatorial position. For these 196 cases, the previously established model holds true. Polar, small 197 groups, however, show an increased preference for the axial 198 position due to anomeric effects. The competing orbital 199 interaction between the lone pair on the piperidine nitrogen 200 and the $\sigma^{*}$ of both methyl $\mathrm{C}-\mathrm{H}(\mathrm{D})$ and 2-C-R bonds weakens 201 the rotameric asymmetry, leading to a reduced $\Delta \delta$ (Figure 5).
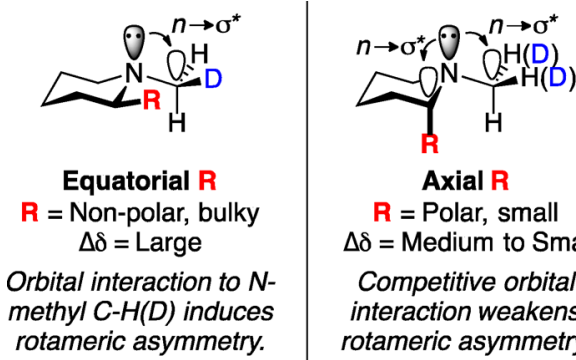

Axial R

$\mathbf{R}=$ Polar, small

$\Delta \delta=$ Medium to Small

Competitive orbital

interaction weakens

rotameric asymmetry.

Figure 5. Qualitative model for evaluating small chemical shift differences in 2-substituted 1-(methyl- $d$ )-piperidines.

202 Next, we compute the proton chemical shift difference in the $203 \mathrm{CH}_{2} \mathrm{D}$ group of tricarbonyl( 1-chloro-2 204 deuteriomethylbenzene)chromium(0) (Figure 1). It is known 205 that coordination of metals to arenes results in a dramatic 206 withdrawal of electron density from the arene and enhanced 207 acidity of benzylic protons. ${ }^{33,34}$ The $\mathrm{Cr}(\mathrm{CO})_{3}$ moiety of 208 tricarbonyl(1-chloro-2-deuteriomethylbenzene) chromium $(0)$ 209 facilitates dissociation at the benzylic group, provides facial 210 selectivity on the arene ring, and stabilizes both benzylic cations 211 and anions formed as reactive intermediates. ${ }^{35-37}$ It is 212 conceivable that the asymmetry in the complex could be 213 coupled with selective $\mathrm{C}-\mathrm{H}(\mathrm{D})$ bond weakening induced by 214 the $\mathrm{Cr}(\mathrm{CO})_{3}$ moiety to generate a small but observable $\mathrm{CH}_{2} \mathrm{D}$ 215 proton chemical shift difference. In fact, Siegel and Restelli 216 previously reported chirotopicity of the methyl group in 217 tricarbonyl(1-chloro-2-deuteriomethylbenzene) chromi$218 \mathrm{um}(0) .{ }^{10}$ An experimentally observed chemical shift difference of $8.0 \pm 0.4 \mathrm{ppb}$ is observed in benzene between the $\mathrm{CH}_{2} \mathrm{D} 219$ protons, consistent with their findings. ${ }^{6}$

The protocol for computing the $\Delta \delta$ in the 2-substituted 1- 221 (methyl- $d$ )piperidine study (vide supra) was also employed 222 here. However, the PCM for dichloromethane was substituted 223 with that of benzene to best align with experimental conditions. 224 We located two isomers of tricarbonyl(1-chloro-2- 225 deuteriomethylbenzene) chromium $(0)$, one of which has a 226 carbonyl bisecting the ortho methyl and chloro substituents 227 (Table 2). A slight thermodynamic preference is observed for 228 t2

Table 2. Mole Fractions $(\chi)$ of $\mathrm{CH}_{2} \mathrm{D}$ Rotamers Across Conformers, and Corresponding Computational (comp) and Experimental (exp) Chemical Shift Differences $(\Delta \delta)$ between Prochiral $\mathrm{CH}_{2} \mathrm{D}$ Protons in Tricarbonyl(1-chloro-2deuteriomethylbenzene) $\operatorname{chromium}(0)^{a}$
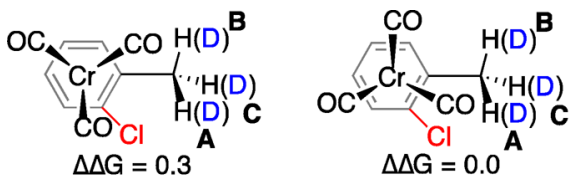
Averaged Chem- ical Shift Differ- ences $\left(\Delta \delta, \mathrm{H}_{\mathrm{R}}-\mathrm{H}_{\mathrm{S}}\right)$ in $p p b$

$\begin{array}{cccccccc}\chi_{\mathrm{A}} & \chi_{\mathrm{B}} & \chi_{\mathrm{C}} & \chi_{\mathrm{A}} & \chi_{\mathrm{B}} & \chi_{\mathrm{C}} & \Delta \delta_{\text {comp }} & \Delta \delta_{\text {exp }}{ }^{b} \\ 0.125 & 0.122 & 0.116 & 0.218 & 0.214 & 0.205 & 12.1 & 8.0\end{array}$

${ }^{a}$ All experimental NMR spectra provided in the Supporting Information. ${ }^{32}$. ${ }^{b}$ Experimentally determined chemical shifts reported to $\pm 0.4 \mathrm{ppb}$ precision.

the bisecting conformer $(\Delta \Delta G=0.3 \mathrm{kcal} / \mathrm{mol})$. However, both 229 conformers are predicted to equilibrate readily at room 230 temperature $\left(\Delta G^{\ddagger}=2.1 \mathrm{kcal} / \mathrm{mol}\right.$ from lowest energy 231 conformer). ${ }^{23}$ When computing $\Delta \delta$, we included the weighted 232 chemical shift of the rotamers in each conformer. A $\Delta \delta$ of 12.1233 $\mathrm{ppb}$ is predicted, in reasonable agreement with experiments. 234

\section{CONCLUSION}

In conclusion, we have shown that in the 2-substituted 1- 236 (methyl- $d$ )piperidine family, stereoelectronic effects of the 2-237 substituents on the piperidine ring strongly influence proton 238 chemical shift differences. The polarity and size of the 2-239 substituent affects the 1,2-stereoisomeric relationship and 240 consequently the strength of the rotational asymmetry within 241 the $\mathrm{CH}_{2} \mathrm{D}$ group. Furthermore, our tricarbonyl(1-chloro-2- 242 deuteriomethylbenzene)chromium(0) results suggest that 243 computational predictions of these small proton shift differ- 244 ences can be extended to a wider variety of $\mathrm{CH}_{2} \mathrm{D}$-containing 245 compounds. We continue to investigate related species in our 246 laboratories, and hope that this study aids the future synthesis 247 and development of molecular agents bearing accessible long- 248 lived states.

\section{EXPERIMENTAL SECTION}

General. Chemicals including labeled materials were purchased 251 from Aldrich Chemical Co. and used without further purification. All 252 reactions were performed in an inert argon or nitrogen atmosphere. 253 ${ }^{1} \mathrm{H}$ NMR and ${ }^{13} \mathrm{C}$ NMR spectra were recorded in $\mathrm{CDCl}_{3}$ or $\mathrm{D}_{2} \mathrm{O} 254$ solution using a Bruker DPX 400 (400 and $101 \mathrm{MHz}$ respectively) 255 spectrometers. All spectra were reprocessed using ACD/Laboratories 256 software version: 2014. Electron impact (EI) low-resolution mass 257 spectra were recorded on a Trace 2000 Series GC-MS. Electrospray 258 (ES) low-resolution mass spectra were recorded on a Waters ZMD or 259 Waters TQD quadrupole spectrometer. Newly developed syntheses of 260 
261 2-ethynylpiperidine ${ }^{38}$ and 2-phenylpiperidine, ${ }^{39}$ both known com262 pounds, will be reported elsewhere.

263 2-Ethyl-1-(methyl-d)piperidine. To 2-ethylpiperidine $(500 \mathrm{mg}$, $2644.42 \mathrm{mmol}$ ) was added formaldehyde $\left(1.08 \mathrm{~mL}\right.$ of $37 \mathrm{wt} \%$ in $\mathrm{H}_{2} \mathrm{O}$, $265568 \mathrm{mg}, 13.2 \mathrm{mmol}, 3.0$ equiv) followed by careful addition of formic 266 acid- $\mathrm{d}_{2}\left(0.83 \mathrm{~mL}\right.$ of $95 \%$ in $\mathrm{D}_{2} \mathrm{O}, 22.0 \mathrm{mmol}, 5.0$ equiv), and the 267 reaction heated at $85{ }^{\circ} \mathrm{C}$ (using a water bath) for $3 \mathrm{~h}$. The reaction was 268 cooled to rt, water $(4 \mathrm{~mL})$ added, and the acidic aqueous reaction was 269 extracted with pet. ether. The aqueous layer was basified to $\mathrm{pH} 12$ 270 using $6 \mathrm{M} \mathrm{NaOH}$ and extracted with $\mathrm{Et}_{2} \mathrm{O}(\times 5)$. The combined $\mathrm{Et}_{2} \mathrm{O}$ 271 extractions were dried $\left(\mathrm{MgSO}_{4}\right)$ and concentrated on a rotary 272 evaporator without vacuum (bath temp $=40{ }^{\circ} \mathrm{C}$ ) to give the title 273 compound as a pale yellow clear oil (447 mg, $3.49 \mathrm{mmol}, 79 \%) .{ }^{1} \mathrm{H}$ $274 \mathrm{NMR}\left(400 \mathrm{MHz}, \mathrm{CDCl}_{3}\right) \delta 2.85$ (br d, $J=11.5 \mathrm{~Hz}, 1 \mathrm{H}$ ), $2.28-2.15$ $275(\mathrm{~m}, 2 \mathrm{H}), 2.11-2.01(\mathrm{~m}, 1 \mathrm{H}), 1.82-1.68(\mathrm{~m}, 2 \mathrm{H}), 1.68-1.53(\mathrm{~m}, 4 \mathrm{H})$, $2761.46-1.35(\mathrm{~m}, 1 \mathrm{H}), 1.34-1.18(\mathrm{~m}, 2 \mathrm{H}), 0.88(\mathrm{t}, \mathrm{J}=7.4 \mathrm{~Hz}, 3 \mathrm{H}) \mathrm{ppm}$; $277{ }^{13} \mathrm{C}$ NMR $\left(101 \mathrm{MHz}, \mathrm{CDCl}_{3}\right) \delta 65.0,57.3,42.7\left(\mathrm{t}, J_{\mathrm{D}, \mathrm{C}}=20.54 \mathrm{~Hz}\right.$, $\left.278 \mathrm{CH}_{2} \mathrm{D}\right), 30.1,26.0,25.5,24.5,9.4 \mathrm{ppm}$; MS EI $(\mathrm{m} / z) 84.04$ $279\left[\mathrm{C}_{5} \mathrm{H}_{10} \mathrm{~N}^{+\cdot}\right](70 \%) 49.1$ (100\%). HRMS $\left(\mathrm{ES}^{+}\right)$for $\mathrm{C}_{8} \mathrm{H}_{17} \mathrm{DN}$ 280 calculated 129.1497 , found $129.1497 \mathrm{Da}$.

281 2-Methyl-1-(methyl-d)piperidine. To 2-methylpiperidine (844 $282 \mathrm{mg}, 1.00 \mathrm{~mL}, 8.51 \mathrm{mmol}$ ) was added formaldehyde $\left(37 \mathrm{wt} \%\right.$ in $\mathrm{H}_{2} \mathrm{O}$, $2832.07 \mathrm{~mL}, 25.5 \mathrm{mmol}, 3.0$ equiv) followed by careful addition of formic 284 acid- $\mathrm{d}_{2}$ (95\% in $\mathrm{D}_{2} \mathrm{O}, 1.72 \mathrm{~g}, 1.41 \mathrm{~mL}, 34.0 \mathrm{mmol}, 4.0$ equiv), and the 285 reaction heated at $85{ }^{\circ} \mathrm{C}$ (using a water bath) for $3 \mathrm{~h}$. The reaction was 286 cooled to rt, water $(2 \mathrm{~mL})$ was added, and the acidic aqueous reaction 287 was extracted with pet. ether. The aqueous layer was basified to $\mathrm{pH} 12$ 288 using $6 \mathrm{M} \mathrm{NaOH}$ and extracted with $\mathrm{Et}_{2} \mathrm{O}(\times 5)$. The combined $\mathrm{Et}_{2} \mathrm{O}$ 289 extractions were dried $\left(\mathrm{MgSO}_{4}\right)$ and concentrated on a rotary 290 evaporator without vacuum (bath temp $=40{ }^{\circ} \mathrm{C}$ ) to give a pale yellow 291 oil. Purification by Kugelrohr distillation (oven temperature 150-160 $292{ }^{\circ} \mathrm{C}$ ) to give the title compound as a clear oil $(696 \mathrm{mg}, 6.09 \mathrm{mmol}$, $29372 \%) .{ }^{1} \mathrm{H}$ NMR (400 MHz, $\left.\mathrm{CDCl}_{3}\right) \delta 2.80-2.76(\mathrm{~m}, 1 \mathrm{H}), 2.18(\mathrm{~d}$, $\left.294 J_{H, D}=1.0 \mathrm{~Hz}, 2 \mathrm{H}\right), 2.01-1.95(\mathrm{~m}, 1 \mathrm{H}), 1.88-1.80(\mathrm{~m}, 1 \mathrm{H}), 1.70-$ $2951.48(\mathrm{~m}, 4 \mathrm{H}), 1.29-1.16(\mathrm{~m}, 2 \mathrm{H}), 1.04(\mathrm{~d}, J=6.1 \mathrm{~Hz}, 3 \mathrm{H}) \mathrm{ppm} ;{ }^{13} \mathrm{C}$ $296 \operatorname{NMR}\left(101 \mathrm{MHz}, \mathrm{CDCl}_{3}\right) \delta 59.3,57.0,42.9\left(\mathrm{t}, J_{D, C}=20.5 \mathrm{~Hz}, \mathrm{CH}_{2} \mathrm{D}\right)$, 297 34.6, 26.1, 24.5, $20.2 \mathrm{ppm}$. MS EI $(\mathrm{m} / z) 84.07\left[\mathrm{C}_{5} \mathrm{H}_{10} \mathrm{~N}^{+}\right](60 \%)$.

298 2-Trifluoromethyl-1-(methyl-d)piperidine. To 2-trifluorome299 thylpiperidine $(970 \mathrm{mg}, 6.33 \mathrm{mmol})$, was added formaldehyde $(1.54$ $300 \mathrm{~mL}$ of $37 \%$ in $\mathrm{H}_{2} \mathrm{O}, 18.99 \mathrm{mmol}, 3.0$ equiv) followed by careful 301 addition of formic acid- $\mathrm{d}_{2}(1.2 \mathrm{~mL}, 31.7 \mathrm{~mol}, 5.0$ equiv). The reaction 302 was heated at $85{ }^{\circ} \mathrm{C}$ (using a water bath) for $4 \mathrm{~h}$ before being cooled 303 to rt. Water $(2 \mathrm{~mL})$ was added and the acidic aqueous reaction 304 extracted with pet. ether. The aqueous layer was basified to $\mathrm{pH} 12$ 305 using $6 \mathrm{M} \mathrm{NaOH}$ and extracted with $\mathrm{Et}_{2} \mathrm{O}(\times 5)$. The combined $\mathrm{Et}_{2} \mathrm{O}$ 306 extractions were dried $\left(\mathrm{Na}_{2} \mathrm{SO}_{4}\right)$ and concentrated on a rotary 307 evaporator without vacuum (bath temp $=40{ }^{\circ} \mathrm{C}$ ). This gave the title 308 compound as a colorless oil (948 mg, $5.64 \mathrm{mmol}, 89 \%) .{ }^{1} \mathrm{H}$ NMR $309\left(400 \mathrm{MHz}, \mathrm{CDCl}_{3}\right) \delta 2.89(\mathrm{dq}, J=11.9,4.3 \mathrm{~Hz}, 1 \mathrm{H}), 2.68-2.59(\mathrm{~m}$, $3101 \mathrm{H}), 2.39$ (q, $J=1.8 \mathrm{~Hz}, 2 \mathrm{H}), 2.27(\mathrm{dt}, J=11.8,6.8 \mathrm{~Hz}, 1 \mathrm{H}), 1.88-$ $3111.82(\mathrm{~m}, 1 \mathrm{H}), 1.78-1.71(\mathrm{~m}, 1 \mathrm{H}), 1.66-1.55(\mathrm{~m}, 3 \mathrm{H}), 1.37-1.27(\mathrm{~m}$, $3121 \mathrm{H}) \mathrm{ppm} .{ }^{13} \mathrm{C}$ NMR $\left(101 \mathrm{MHz}, \mathrm{CDCl}_{3}\right) \delta 126.7(\mathrm{q}, J=285.4 \mathrm{~Hz})$, $31363.9(\mathrm{q}, J=25.7 \mathrm{~Hz}), 55.7,44.0(\mathrm{tq}, J=20.5,2.2 \mathrm{~Hz}), 25.2(\mathrm{q}, J=3.0$ $314 \mathrm{~Hz}), 25.0,22.3 \mathrm{ppm} ;{ }^{19} \mathrm{~F}$ NMR $\left(376 \mathrm{MHz}, \mathrm{CDCl}_{3}\right) \delta 68.4 \mathrm{ppm}$; MS $315 \mathrm{ESI}^{+}(\mathrm{m} / z) 169.28[\mathrm{M}+\mathrm{H}]^{+}$. HRMS $\left(\mathrm{ES}^{+}\right)$for $\mathrm{C}_{7} \mathrm{H}_{12} \mathrm{DF}_{3} \mathrm{~N}$ calculated 316 169.1057, found $169.1059 \mathrm{Da}$.

317 2-Ethynyl-1-(methyl- $d$ )piperidine. To 2-ethynylpiperidine (70 $318 \mathrm{mg}, 0.64 \mathrm{mmol})$ was added formaldehyde $\left(157 \mu \mathrm{L}\right.$ of 37 wt \% in $\mathrm{H}_{2} \mathrm{O}$, $31958 \mathrm{mg}, 1.93 \mathrm{mmol}, 3.0$ equiv) followed by careful addition of formic 320 acid- $\mathrm{d}_{2}\left(120 \mu \mathrm{L}\right.$ of $95 \%$ in $\mathrm{D}_{2} \mathrm{O}, 3.20 \mathrm{mmol}, 5.0$ equiv $)$, and the 321 reaction heated at $85{ }^{\circ} \mathrm{C}$ (using a water bath) for $3 \mathrm{~h}$. The reaction was 322 cooled to rt, water $(1 \mathrm{~mL})$ added, and the acidic aqueous reaction was 323 extracted with pet. ether. The aqueous layer was basified to $\mathrm{pH} 12$ 324 using $6 \mathrm{M} \mathrm{NaOH}$ and extracted with $\mathrm{Et}_{2} \mathrm{O}(\times 5)$. The combined $\mathrm{Et}_{2} \mathrm{O}$ 325 extractions were dried $\left(\mathrm{MgSO}_{4}\right)$ and concentrated on a rotary 326 evaporator without vacuum (bath temp $=40{ }^{\circ} \mathrm{C}$ ) to give the title 327 compound as a pale yellow oil $(67 \mathrm{mg}, 0.54 \mathrm{mmol}, 85 \%) .{ }^{1} \mathrm{H}$ NMR $328\left(400 \mathrm{MHz}, \mathrm{CDCl}_{3}\right) \delta 3.42-3.33(\mathrm{~m}, 1 \mathrm{H}), 2.63-2.48(\mathrm{~m}, 1 \mathrm{H}), 2.37-$ $3292.27(\mathrm{~m} 4 \mathrm{H}), 1.87-1.71(\mathrm{~m}, 2 \mathrm{H}), 1.68-1.42(\mathrm{~m}, 4 \mathrm{H})$ ppm; MS EI $330(\mathrm{~m} / z) 1240.0\left[\mathrm{M}^{+\cdot}\right](20 \%) .{ }^{13} \mathrm{C} \mathrm{NMR}\left(101 \mathrm{MHz}, \mathrm{CDCl}_{3}\right) \delta 77.2$,
73.5, 68.0, 53.8, $43.9\left(\mathrm{t}, J_{D, C}=20.5 \mathrm{~Hz}, \mathrm{CH}_{2} \mathrm{D}\right), 31.5,25.6,20.5 \mathrm{ppm} ; 331$ MS EI $(m / z) 1240.0\left[\mathrm{M}^{+}\right]$(20\%). HRMS $\left(\mathrm{ES}^{+}\right)$for $\mathrm{C}_{8} \mathrm{H}_{13} \mathrm{DN} 332$ calculated 125.1184, found 125.1183 Da.

Ethyl 1-(Methyl-d)piperidine-2-carboxylate. To ethylpipecoli- 334 nate $(980 \mathrm{mg}, 6.24 \mathrm{mmol})$ was added formaldehyde $(1.50 \mathrm{~mL}$ of $37 \mathrm{wt} 335$ \% in $\mathrm{H}_{2} \mathrm{O}, 568 \mathrm{mg}, 19.08 \mathrm{mmol}, 3.0$ equiv) followed by careful 336 addition of formic acid- $\mathrm{d}_{2}\left(1.20 \mathrm{~mL}\right.$ of $95 \%$ in $\mathrm{D}_{2} \mathrm{O}, 31.80 \mathrm{mmol}, 5.0337$ equiv), and the reaction heated at $85{ }^{\circ} \mathrm{C}$ (using a water bath) for $3 \mathrm{~h} .338$ The reaction was cooled to rt, water $(2 \mathrm{~mL})$ added, and the acidic 339 aqueous reaction was extracted with pet. ether. The aqueous layer was 340 basified to $\mathrm{pH} 12$ using $6 \mathrm{M} \mathrm{NaOH}$ and extracted with $\mathrm{Et}_{2} \mathrm{O}(\times 5) .341$ The combined $\mathrm{Et}_{2} \mathrm{O}$ extractions were dried $\left(\mathrm{MgSO}_{4}\right)$ and concen- 342 trated on a rotary evaporator without vacuum (bath temp $=40^{\circ} \mathrm{C}$ ) to 343 give the title compound as a clear oil (977 $\mathrm{mg}, 5.68 \mathrm{mmol}, 91 \%) .{ }^{1} \mathrm{H} 344$ NMR (400 MHz, $\left.\mathrm{CDCl}_{3}\right) \delta 4.18(\mathrm{q}, J=7.1 \mathrm{~Hz}, 2 \mathrm{H}), 3.00-2.84(\mathrm{~m}, 345$ $1 \mathrm{H}), 2.68(\mathrm{dd}, J=10.3,3.2 \mathrm{~Hz}, 1 \mathrm{H}), 2.20(\mathrm{br} \mathrm{s}, 2 \mathrm{H}), 2.13-1.96(\mathrm{td}, J 346$ $=11.2,3.9 \mathrm{~Hz}, 1 \mathrm{H}), 1.86-1.55(\mathrm{~m}, 5 \mathrm{H}), 1.34-1.23(\mathrm{~m}, 1 \mathrm{H}), 1.25(\mathrm{t}, J 347$ $=7.1 \mathrm{~Hz}, 3 \mathrm{H}) \mathrm{ppm} ;{ }^{13} \mathrm{C} \mathrm{NMR}\left(101 \mathrm{MHz}, \mathrm{CDCl}_{3}\right) \delta 173.5,67.9,60.5,348$ 55.0, 43.9 (t, $J_{D, C}=20.5 \mathrm{~Hz}, \mathrm{CH}_{2} \mathrm{D}$ ), 29.7, 25.1, 22.9, 14.2 ppm; MS 349 $\mathrm{ESI}^{+}(\mathrm{m} / z) 173.3[\mathrm{M}+\mathrm{H}]^{+}$. HRMS $\left(\mathrm{ES}^{+}\right)$for $\mathrm{C}_{9} \mathrm{H}_{17} \mathrm{DNO}_{2}$ calculated 350 173.1395 , found $173.1395 \mathrm{Da}$.

351

2-Phenyl-1-(methyl- $d$ )piperidine. To 2-phenylpiperidine (1.00 352 g, $6.21 \mathrm{mmol})$, formaldehyde $\left(1.51 \mathrm{~mL}\right.$ of $37 \%$ in $\mathrm{H}_{2} \mathrm{O}, 18.63 \mathrm{mmol}, 353$ 3.0 equiv) was added followed by careful addition of formic acid- $\mathrm{d}_{2} 354$ ( $1.17 \mathrm{~mL}$ of $95 \%$ in $\mathrm{D}_{2} \mathrm{O}, 31.05 \mathrm{mmol}, 5.0$ equiv). The reaction was 355 heated at $85{ }^{\circ} \mathrm{C}$ (using a water bath) for $4 \mathrm{~h}$ before being cooled to rt. 356 Water $(2 \mathrm{~mL})$ was added and the acidic aqueous reaction was 357 extracted with pet. ether. The aqueous layer was basified to $\mathrm{pH} 12358$ using $6 \mathrm{M} \mathrm{NaOH}$ and extracted with $\mathrm{Et}_{2} \mathrm{O}(\times 5)$. The combined $\mathrm{Et}_{2} \mathrm{O} 359$ extractions were dried $\left(\mathrm{Na}_{2} \mathrm{SO}_{4}\right)$ and concentrated on a rotary 360 evaporator without vacuum (bath temp $=40{ }^{\circ} \mathrm{C}$ ). This gave the title 361 compound as a yellow oil $(921 \mathrm{mg}, 5.23 \mathrm{mmol}, 84 \%) .{ }^{1} \mathrm{H}$ NMR (400 362 $\left.\mathrm{MHz}, \mathrm{CDCl}_{3}\right) \delta 7.28-7.18(\mathrm{~m}, 5 \mathrm{H}) 2.99(\mathrm{br} \mathrm{d}, 1 \mathrm{H}, J=11.6), 2.71363$ (dd, $1 \mathrm{H}, J=11.0,3.0 \mathrm{~Hz}), 2.10-2.05(\mathrm{~m}, 1 \mathrm{H}), 1.95(\mathrm{~s}, 2 \mathrm{H}), 1.83-364$ $1.12(\mathrm{~m}, 6 \mathrm{H}) \mathrm{ppm} ;{ }^{13} \mathrm{C}$ NMR $\left(101 \mathrm{MHz}, \mathrm{CDCl}_{3}\right) \delta 144.9,128.4,365$ 127.4, 126.9, 71.2, 57.5, $45.6\left(\mathrm{t}, J_{D, C}=20.5 \mathrm{~Hz}, \mathrm{CH}_{2} \mathrm{D}\right), 35.9,26.2,25.0366$ ppm; MS ESI ${ }^{+}(m / z) 177.3[\mathrm{M}+\mathrm{H}]^{+}$. HRMS $\left(\mathrm{ES}^{+}\right)$for $\mathrm{C}_{12} \mathrm{H}_{17} \mathrm{DN} 367$ calculated 177.1497, found 177.1499 Da.

$\alpha$-Deuterio-o-chlorotoluene ${ }^{40}$ To 2-chlorobenzyl bromide 368 $(2.00 \mathrm{~g}, 9.73 \mathrm{mmol})$ in DMSO- $d_{6}(6 \mathrm{~mL})$ at $0{ }^{\circ} \mathrm{C}$ was added sodium 370 borodeuteride $(0.82 \mathrm{~g}, 19.46 \mathrm{mmol})$ portion-wise. The reaction 371 formed a white solid that was stirred for $4 \mathrm{~h}$ at rt. The reaction was 372 quenched with methanol $(0.75 \mathrm{~mL}), \mathrm{Et}_{2} \mathrm{O}$ was added, and the organic 373 layer washed with $\mathrm{H}_{2} \mathrm{O}(\times 3)$, brine and then dried $\left(\mathrm{MgSO}_{4}\right)$. The 374 solvent was removed in vacuo at rt. The resultant oil was purified by 375 Kugelrohr distillation to give the title compound as a colorless oil 376 (0.89 g, $6.98 \mathrm{mmol}, 72 \%)$. Bpt $157-159{ }^{\circ} \mathrm{C} .{ }^{1} \mathrm{H}$ NMR (400 MHz, 377 $\left.\mathrm{CDCl}_{3}\right) \delta=7.36(\mathrm{dd}, J=7.1,1.7 \mathrm{~Hz}, 1 \mathrm{H}), 7.27-7.12(\mathrm{~m}, 3 \mathrm{H}), 2.41-378$ $2.37\left(\mathrm{t}, J_{\mathrm{HD}}=7.1 \mathrm{~Hz}, 2 \mathrm{H}\right) ;{ }^{13} \mathrm{C} \mathrm{NMR}\left(101 \mathrm{MHz}, \mathrm{CDCl}_{3}\right) \delta=136.0,379$ $134.4,130.9,129.0,127.1,126.5,19.7 \mathrm{ppm}\left(\mathrm{t}, J_{\mathrm{CD}}=19.8 \mathrm{~Hz}\right)$. GC-MS 380 (EI) $\mathrm{m} / z(100 \%) 126.8 \mathrm{C}_{7} \mathrm{H}_{6} \mathrm{DCl}^{+}$, $91.9 \mathrm{C}_{7} \mathrm{H}_{6} \mathrm{D}^{+}$.

Tricarbonyl(1-chloro-2-deuteriomethylbenzene)chromium- 382 (0). ${ }^{41} \alpha$-Deuterio- 0 -chlorotoluene (1, $0.38 \mathrm{~g}, 3.0 \mathrm{mmol}$ ) and 383 hexacarbonyl chromium(0) (0.33 g, $1.5 \mathrm{mmol})$ in dibutyl ether/ 384 THF $(9: 1,7.5 \mathrm{~mL})$ was heated at reflux for $36 \mathrm{~h}$. The reaction was 385 allowed to cool, $\mathrm{Et}_{2} \mathrm{O}$ was added, and the solution passed through a 386 short column of alumina, eluting with $\mathrm{Et}_{2} \mathrm{O}$. The solvent was removed 387 in vacuo and the crude yellow solid recrystallized from $\mathrm{Et}_{2} \mathrm{O}$ /pentane 388 and the yellow crystals washed with cold pentane. The title compound 389 was obtained as a yellow crystalline solid (0.28 g, $1.06 \mathrm{mmol}, 35 \%) .390$ Mpt $100-102{ }^{\circ} \mathrm{C} .{ }^{1} \mathrm{H}$ NMR $\left(400 \mathrm{MHz}, \mathrm{C}_{6} \mathrm{D}_{6}\right) \delta=4.75$ (br d, $J=6.2391$ $\mathrm{Hz}, 1 \mathrm{H}), 4.30(\mathrm{br} \mathrm{d}, J=6.0 \mathrm{~Hz}, 1 \mathrm{H}), 4.18(\mathrm{br} \mathrm{t}, J=6.1 \mathrm{~Hz}, 1 \mathrm{H}), 4.07392$ (br t, $J=6.1 \mathrm{~Hz}, 1 \mathrm{H}), 1.71($ br s, $2 \mathrm{H}) ;{ }^{13} \mathrm{C}$ NMR $\left(101 \mathrm{MHz}, \mathrm{C}_{6} \mathrm{D}_{6}\right) \delta 393$ $=112.0,106.3,93.9,93.3,91.0,90.4,19.0 \mathrm{ppm}\left(\mathrm{t}, J_{\mathrm{CD}}=19.9 \mathrm{~Hz}\right)$. GC- 394 MS (EI) $m / z(100 \%) 126.8 \mathrm{C}_{7} \mathrm{H}_{6} \mathrm{DCl}^{+}$.

Sample Preparation. 2-Substituted 1-(methyl- $d$ )-piperidines were 396 dissolved in $0.5 \mathrm{~mL}$ of $\mathrm{CD}_{2} \mathrm{Cl}_{2}$ to a concentration of $0.1 \mathrm{M}$. $12.58 \mathrm{mg} 397$ of tricarbonyl(1-chloro-2-deuteriomethylbenzene)chromium(0) was 398 dissolved in $0.5 \mathrm{~mL}$ of $\mathrm{C}_{6} \mathrm{D}_{6}$ to a concentration of $0.1 \mathrm{M}$. TMS 399 vapor was added to all samples as a reference compound. 


\section{ASSOCIATED CONTENT}

\section{S Supporting Information}

403 The Supporting Information is available free of charge on the 404 ACS Publications website at DOI: 10.1021/acs.joc.7b01356.

405 Computational protocols, benchmark studies, shielding 406 constants, coordinates, energies, vibrational frequencies, 407 experimental ${ }^{1} \mathrm{H},{ }^{13} \mathrm{C}$, and, where appropriate, ${ }^{19} \mathrm{~F}$ NMR 408 spectra (PDF)

\section{AUTHOR INFORMATION}

\section{Corresponding Author}

$411 *$ daniel.o'leary@pomona.edu

412 ORCID $\odot$

413 O. Maduka Ogba: 0000-0002-5718-6761

414 Malcolm H. Levitt: 0000-0001-9878-1180

415 Notes

416 The authors declare no competing financial interest.

\section{ACKNOWLEDGMENTS}

418 O.M.O., D.A.K., S.C., and D.J.O. acknowledge support from 419 Pomona College. S.J.E., L.J.B., S.S., and M.H.L acknowledge 420 support from the Engineering and Physical Sciences Research 421 Council (UK), grant codes EP/N002482 and EP/L505067/1, 422 the Wolfson Foundation, and Bruker Biospin (UK).

\section{REFERENCES}

424 (1) For recent reviews of LLS, see: (a) Pileio, G. Prog. Nucl. Magn. 425 Reson. Spectrosc. 2017, 98-99, 1-19. (b) Levitt, M. H. Annu. Rev. Phys. 426 Chem. 2012, 63 (1), 89-105.

427 (2) (a) Stevanato, G.; Hill-Cousins, J. T.; Hakansson, P.; Roy, S. S.; 428 Brown, L. J.; Brown, R. C. D.; Pileio, G.; Levitt, M. H. Angew. Chem., 429 Int. Ed. 2015, 54, 3740-3743. (b) Pileio, G.; Dumez, J.-N.; Pop, I.-A.; 430 Hill-Cousins, J. T.; Brown, R. C. D. J. Magn. Reson. 2015, 252, 130431 134. (c) Dumez, J.-N.; Hill-Cousins, J. T.; Brown, R. C. D.; Pileio, G. J. 432 Magn. Reson. 2014, 246, 27-30. (d) DeVience, S. J.; Walsworth, R. L.; 433 Rosen, M. S. Phys. Rev. Lett. 2013, 111 (17), 173002. (e) Feng, Y.; 434 Davis, R. M.; Warren, W. S. Nat. Phys. 2012, 8, 831-837. (f) Tayler, 435 M. C. D.; Levitt, M. H. Phys. Chem. Chem. Phys. 2011, 13 (13), 5556436 5560. (g) Pileio, G.; Carravetta, M.; Levitt, M. H. Proc. Natl. Acad. Sci. 437 U. S. A. 2010, 107 (40), 17135-17139. (h) Warren, W. S.; Jenista, E.; 438 Branca, R. T.; Chen, X. Science 2009, 323 (5922), 1711-1714. 439 (i) Pileio, G.; Carravetta, M.; Hughes, E.; Levitt, M. H. J. Am. Chem. 440 Soc. 2008, 130, 12582-12583. (j) Carravetta, M.; Johannessen, O. G.; 441 Levitt, M. H. Phys. Rev. Lett. 2004, 92, 153003.

442 (3) (a) Ji, X.; Bornet, A.; Vuichoud, B.; Milani, J.; Gajan, D.; Rossini, 443 A. J.; Emsley, L.; Bodenhausen, G.; Jannin, S. Nat. Commun. 2017, 8, 444 13975. (b) Rodrigues, T. B.; Serrao, E. M.; Kennedy, B. W. C.; Hu, D.445 E.; Kettunen, M. I.; Brindle, K. M. Nat. Med. 2013, 20 (1), 93-97. 446 (c) Ardenkjaer-Larsen, J.-H.; Fridlund, B.; Gram, A.; Hansson, G.; 447 Hansson, L.; Lerche, M. H.; Servin, R.; Thaning, M.; Golman, K. Proc. 448 Natl. Acad. Sci. U. S. A. 2003, 100, 10158-10163.

449 (4) For applications of hyperpolarization, see: (a) Nelson, S. J.; 450 Kurhanewicz, J.; Vigneron, D. B.; Larson, P. E. Z.; Harzstark, A. L.; 451 Ferrone, M.; van Criekinge, M.; Chang, J. W.; Bok, R.; Park, I.; Reed, 452 G.; Carvajal, L.; Small, E. J.; Munster, P.; Weinberg, V. K.; Ardenkjaer453 Larsen, J. H.; Chen, A. P.; Hurd, R. E.; Odegardstuen, L.-I.; Robb, F. J.; 454 Tropp, J.; Murray, J. A. Sci. Transl. Med. 2013, 5 (198), 198ra108455 198ra108. (b) DeVience, S. J.; Walsworth, R. L.; Rosen, M. S. NMR 456 Biomed. 2013, 26 (10), 1204-1212. (c) Bornet, A.; Ahuja, P.; Sarkar, 457 R.; Fernandes, L.; Hadji, S.; Lee, S. Y.; Haririnia, A.; Fushman, D.; 458 Bodenhausen, G.; Vasos, P. R. ChemPhysChem 2011, 12 (15), 2729459 2734. (d) Ahuja, P.; Sarkar, R; Vasos, P. R.; Bodenhausen, G. J. Am. 460 Chem. Soc. 2009, 131 (22), 7498-7499.

461 (5) Elliott, S. J.; Brown, L. J.; Dumez, J.-N.; Levitt, M. H. Phys. Chem. 462 Chem. Phys. 2016, 18 (27), 17965-17972.
(6) Elliott, S. J.; Brown, L. J.; Dumez, J.-N.; Levitt, M. H. J. Magn. 463 Reson. 2016, 272, 87-90.

464

(7) Anet, F. A. L.; Kopelevich, M. J. Am. Chem. Soc. 1989, 111 (9), 465 3429-3431. 466

(8) Allen, B. D.; O’Leary, D. J. J. Am. Chem. Soc. 2003, 125 (30), 467 9018-9019.

(9) Allen, B. D.; Cintrat, J.-C.; Faucher, N.; Berthault, P.; Rousseau, 469 B.; O'Leary, D. J. J. Am. Chem. Soc. 2005, 127 (1), 412-420. 470 (10) Restelli, A.; Siegel, J. S. J. Am. Chem. Soc. 1992, 114 (3), 1091- 471 1092.

(11) Lodewyk, M. W.; Siebert, M. R.; Tantillo, D. J. Chem. Rev. 2012, 473 112 (3), 1839-1862.

(12) Halgren, T. A. J. Comput. Chem. 1996, 17 (5-6), 490-519.

(13) Schrodinger Release 2014-3: MacroModel; Schrödinger, LLC: 476 New York, NY, 2014.

(14) Frisch, M. J.; Trucks, G. W.; Schlegel, H. B.; Scuseria, G. E.; 478 Robb, M. A.; Cheeseman, J. R.; Scalmani, G.; Barone, V.; Mennucci, 479 B.; Petersson, G. A.; Nakatsuji, H.; Caricato, M.; Li, X.; Hratchian, H. 480 P.; A. F. Izmaylov, A. F.; Bloino, J.; Zheng, G.; Sonnenberg, J. L.; 481 Hada, M.; Ehara, M.; Toyota, K.; Fukuda, R.; Hasegawa, J.; Ishida, M.; 482 Nakajima, T.; Honda, Y.; Kitao, O.; Nakai, H.; Vreven, T.; 483 Montgomery, Jr., J. A.; J. E. Peralta, J. E.; Ogliaro, F.; Bearpark, M.; 484 Heyd, J. J.; Brothers, E.; Kudin, K. N.; Staroverov, V. N.; Keith, T.; 485 Kobayashi, R.; Normand, J.; Raghavachari, K.; Rendell, A.; Burant, J. 486 C.; Iyengar, S. S.; Tomasi, J.; Cossi, M.; Rega, N.; Millam, J. M.; Klene, 487 M.; Knox, J. E.; Cross, J. B.; Bakken, V.; Adamo, C.; Jaramillo, J.; 488 Gomperts, R.; Stratmann, R. E.; Yazyev, O.; Austin, A. J.; Cammi, R.; 489 Pomelli, C.; Ochterski, J. W.; Martin, R. L.; Morokuma, K.; 490 Zakrzewski, V. G.; Voth, G. A.; Salvador, P.; Dannenberg, J. J.; 491 Dapprich, S.; Daniels, A. D.; Farkas, O.; Foresman, J. B.; Ortiz, J. V.; 492 Cioslowski, J.; Fox, D. J. Gaussian 09; Gaussian, Inc.: Wallingford, CT, 493 2009.

(15) Chai, J.-D.; Head-Gordon, M. J. Chem. Phys. 2008, 128 (8), 495 084106.

(16) Dunning, T. H., Jr. J. Chem. Phys. 1989, 90 (2), 1007-1023. 497 (17) Miertuš, S.; Scrocco, E.; Tomasi, J. Chem. Phys. 1981, 55 (1), 498 117-129.

(18) Slater, J. C. Phys. Rev. 1951, 81 (3), 385-390. 499

(19) Ditchfield, R.; Hehre, W. J.; Pople, J. A. J. Chem. Phys. 1971, 54501 (2), 724-728.

(20) Hariharan, P. C.; Pople, J. A. Theor. Chim. Acta 1973, 28 (3), 503 $213-222$.

(21) Extensive benchmark of employed theoretical method was 505 performed. See Supporting Information for more details. 506

(22) Isotopic NMR shifts calculated using the Onyx program: 507 Brueckner, A. C.; Cevallos, S. L.; Ogba, O. M.; Walden, D. M.; Meyer, 508 M. P.; O'Leary, D. J.; Cheong, P. H.-Y. Onyx, version 1.0; Oregon 509 State University: Corvallis, OR, USA \& Pomona College: Claremont, 510 CA, USA, 2016.

(23) See Supporting Information for more details.

511

(24) Quantum mechanical structures were optimized at $25{ }^{\circ} \mathrm{C}$ in 513 $\omega \mathrm{B} 97 \mathrm{X} / \mathrm{cc}-\mathrm{pVTZ} / \mathrm{PCM}(\mathrm{DCM}), \mathrm{NMR}$ single points in HF/6- 514 $311+\mathrm{G}(2 \mathrm{~d}, \mathrm{p}) / \mathrm{PCM}(\mathrm{DCM})$.

(25) Anet, F. A. L.; Kopelevich, M. J. Chem. Soc., Chem. Commun. 516 1987, 0 (8), 595-597.

(26) Erxleben, N. D.; Kedziora, G. S.; Urban, J. J. Theor. Chem. Acc. 518 2014, 133 (7), 1491.

(27) Experimental spectrum was fitted using the Mathematica based 520 NMR software package SpinDynamica. SpinDynamica Code for 521 Mathematica, Programmed by Malcolm H. Levitt, with Contributions 522 by Jyrki Rantaharju, Andreas Brinkmann, and Soumya Singha Roy. $<523$ http://www.spindynamica.soton.ac.uk>.

(28) Legault, C. Y. CYLview, 1.0b; Université de Sherbrooke, 2009525 (http://www.cylview.org).

(29) (a) Sandoval-Lira, J.; Fuentes, L.; Quintero, L.; Höpfl, H.; 527 Hernández-Pérez, J. M.; Terán, J. L.; Sartillo-Piscil, F. J. Org. Chem. 528 2015, 80 (9), 4481-4490. (b) Scheiner, S. Phys. Chem. Chem. Phys. 529 2011, 13 (31), 13860-13872. (c) Cannizzaro, C. E.; Houk, K. N. J. 530 Am. Chem. Soc. 2002, 124 (24), 7163-7169. (d) Corey, E. J.; Rohde, J. 531 
532 J. Tetrahedron Lett. 1997, 38 (1), 37-40. For $\mathrm{CH} \cdots \mathrm{O}$ reviews, see: 533 (e) Desiraju, G. R. Acc. Chem. Res. 1996, 29 (9), 441-449. 534 (f) Johnston, R. C.; Cheong, P. H.-Y. Org. Biomol. Chem. 2013, 11 535 (31), 5057-5064.

536 (30) $\mathrm{H}_{2} \mathrm{CH} \cdots \mathrm{FCF}_{2}$ contacts are observed in the dominant stereo537 isomer of $\mathrm{N}-\mathrm{CH}_{2} \mathrm{D}$-2-trifluoromethylpiperidine. However, this is not 538 expected to be stabilizing and hence, not contribute to deshielding 539 effects at the $\mathrm{S}$ position. For a detailed study of $\mathrm{CH} \cdots \mathrm{F}$ interactions, 540 see: Kryachko, E.; Scheiner, S. J. Phys. Chem. A 2004, 108 (13), 25275412535.

542 (31) Hirsch, J. A. In Topics in Stereochemistry; Allinger, N. L., Eliel, E. 543 L., Eds.; John Wiley \& Sons, Inc., 1967; pp 199-222.

544 (32) Quantum mechanical structures were optimized at $25{ }^{\circ} \mathrm{C}$ in $545 \omega \mathrm{B} 97 \mathrm{X} / \mathrm{cc}-\mathrm{pVTZ} / \mathrm{PCM}$ (benzene), NMR single points in $\mathrm{HF} / 6$ $546311+\mathrm{G}(2 \mathrm{~d}, \mathrm{p}) / \mathrm{PCM}$ (benzene).

547 (33) Semmelhack, M. F.; Yamashita, A. J. Am. Chem. Soc. 1980, 102 548 (18), 5924-5926.

549 (34) Trahanovsky, W. S.; Card, R. J. J. Am. Chem. Soc. 1972, 94 (8), $5502897-2898$.

551 (35) Merlic, C. A.; Walsh, J. C.; Tantillo, D. J.; Houk, K. N. J. Am. 552 Chem. Soc. 1999, 121 (15), 3596-3606.

553 (36) Davies, S. G.; Donohoe, T. J. Synlett 1993, 1993 (05), 323-332.

554 (37) Uemura, M. In Organic Reactions; John Wiley \& Sons, Inc., 5552004.

556 (38) Lundkvist, J. R. M.; Vargas, H. M.; Caldirola, P.; Ringdahl, B.; 557 Hacksell, U. J. Med. Chem. 1990, 33 (12), 3182-3189.

558 (39) Prokopcová, H.; Bergman, S. D.; Aelvoet, K.; Smout, V.; 559 Herrebout, W.; Van der Veken, B.; Meerpoel, L.; Maes, B. U. W. 560 Chem. - Eur. J. 2010, 16 (44), 13063-13067.

561 (40) Hutchins, R. O.; Kandasamy, D.; Dux, F.; Maryanoff, C. A.; 562 Rotstein, D.; Goldsmith, B.; Burgoyne, W.; Cistone, F.; Dalessandro, 563 J.; Puglis, J. J. Org. Chem. 1978, 43 (11), 2259-2267.

564 (41) Hörstermann, D.; Schmalz, H.-G.; Kociok-Köhn, G. Tetrahedron 565 1999, 55 (22), 6905-6916. 